\title{
КОМПАКТНЫЕ ПИКОСЕКУНДНЫЕ ДИОДНЫЕ ЛАЗЕРЫ
}

\author{
(C) 2022 г. Е. С. Воропай ${ }^{a}$, К. Ф. Ермалицкая ${ }^{a}$, Ф. А. Ермалицкий ${ }^{a, *}$, \\ А. Е. Радько ${ }^{b}$ Н. В. Ржеуцкий ${ }^{c}$, М. П. Самцов ${ }^{b}$

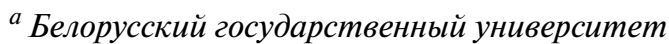 \\ Беларусь, 220030, Минск, просп. Независимости, 4 \\ ${ }^{b}$ Институт прикладных физических проблем им. А.Н. Севченко БГУ \\ Беларусь, 220062, Минск, ул. Курчатова, 7 \\ ${ }^{c}$ Институт физики НАН Беларуси \\ Беларусь, 220072, Минск, просп. Независимости, 68 \\ *e-mail:f.ermalitski@gmail.com \\ Поступила в редакцию 31.05.2021 г. \\ После доработки 06.09.2021 г. \\ Принята к публикации 09.09.2021 г.
}

\begin{abstract}
Приведены электрическая схема, описание конструкции и результаты измерений излучательных ватт-амперных и временных характеристик компактных недорогих излучателей на основе серийных лазерных диодов с длинами волн от 405 до 850 нм, работающих в пикосекундном (70-180 пс) и наносекундном (0.69-1.2 нс) режимах. Оптический излучатель включает в себя задающий кварцевый генератор на основе микроконтроллера (частоты 76 Гц-20/80 МГц), цепь синхронизации, низковольтный (9-12 В) формирователь субнаносекундных электрических импульсов, работающий по методу двойного дифференцирования, цепь накачки с подстраиваемым источником постоянного тока и лазерный диод. Средняя световая мощность при частоте 80 МГц варьируется в пикорежиме от 0.6 до 1.6 мВт, а в нанорежиме - от 6 до 18 мВт. Питание лазеров осуществляется от серийного блока питания 220 B/12 В, 0.25 А, потребляемая мощность 3 Вт, масса 0.2 кг.
\end{abstract}

DOI: $10.31857 / \mathrm{S} 0032816222010232$

Стремительное развитие оптических устройств как в телекоммуникационных отраслях, так и в химических и медицинских исследованиях требует постоянного увеличения скорости обработки информации, а следовательно, частоты следования зондирующих световых сигналов и сокращения их длительности. Это относится и к пикосекундным источникам света для систем времякоррелированного счета фотонов, которые широко используются в различных спектроскопических измерительных системах, в том числе в новейших биомедицинских приложениях типа многомерной FLIM (Fluorescence Lifetime Imaging) диагностики $[1,2]$. Так FLIM-диагностика позволяет непосредственно получать информацию о кон-

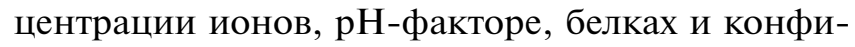
гурации белковых взаимодействий, а также метаболических состояниях клеток и тканей. Это особенно актуально для изучения образования и функционирования так называемых немембранных органелл, которые, по современным представлениям, играют определяющую роль в таких процессах, как регуляция транскрипции, старение, апоптоз, репарация ДНК, противовирусный ответ. Последнее особенно существенно в связи с пандемией, вызванной короновирусом COVID-19.

Во флуорометрии в качестве высокочастотных источников коротких световых сигналов в последнее время все чаще используются диодные источники света, которые более технологичны и энергоэффективны по сравнению с классическими твердотельными и газовыми лазерами и лампами. Высокоскоростные импульсные диодные источники света используются в двух базовых вариантах - светодиодном и лазерном. Светодиодные источники (Pulsed LEDs) более дешевые и пока незаменимы в ультрафиолетовой (у.ф.) области спектра, от 250 до 370 нм. Они могут иметь длительность световых импульсов на полувысоте 600-800 пс при частоте следования сигналов 1040 МГц и средней мощности $0.002-0.1$ мВт. Лазерные диодные излучатели характеризуются лучшими временными характеристиками (длительность на полувысоте 40-140 пс при рабочей частоте до 100 МГц), большей средней мощностью $(0.2-85$ мВт) и острой направленностью излучения. Лидерами в данной отрасли являются фирмы Alphalas, Becker\& Hickl, Edinburg Instruments, Hamamatsu Photonics, Horiba Scientific, 
NKT Photonics, Pico-Quant [3-9]. Рыночная стоимость выпускаемых ими светодиодных излучателей составляет 1300-2800 евро, а лазерных 2700-10400 евро.

Высокая стоимость серийных пикосекундных светодиодных и диодно-лазерных излучателей зачастую является препятствием для применения их в целом ряде практических и научных приложений. Стоимость излучателей формируется за счет высокой цены свето- и лазерных диодов специальных типов, а также специализированной электроники. Ценовой фактор становится особенно существенным при необходимости использования нескольких источников с разными длинами волн. Вместе с тем в современной бытовой электронике широко используются быстродействующие оптические носители информации на основе лазерных диодов: синефиолетовых с длиной волны 405 нм (в лазерных дисках стандарта BLU-RAY), красных с длиной волны 650 нм (в DVD) и инфракрасных с длиной волны 785 нм (в CD). Стоимость применяемых в них серийных лазерных диодов не превышает 10-100 евро, что создает предпосылки для создания дешевых, а значит, и доступных высокоскоростных источников света.

В электронике для накачки субнаносекундных светодиодов и лазерных диодов необходим субнаносекундный генератор электрических импульсов с напряжением 5-12 В и током 30-100 мА. Элементной базой могут служить современные доступные высокочастотные транзисторы с быстродействием до 5-7 ГГц, которые теоретически позволяют формировать импульсы с фронтами порядка 50-100 пс. Предельно короткие фронты электрических импульсов, а также их длительности достигаются в режиме лавинного пробоя транзисторов, что и используется в генераторах накачки большинства вышеуказанных производителей пикосекундных диодных лазеров и в лабораторных условиях [10]. Рабочее напряжение таких генераторов составляет 120-140 В при одинарном включении транзисторов и 200-300 В при каскодном (спаренном последовательном) их включении. Такие генераторы формируют на лазерных диодах суб- и наносекундные импульсы тока амплитудой до 3 А.

Вместе с тем представляется целесообразным использовать более низковольтные, а значит, и более дешевые схемные решения, которые позволяют получать субнаносекундные электрические импульсы с фронтами 80-200 пс. Одним из таких простых вариантов является формирователь субнаносекундных электрических импульсов на основе обострителя фронтов наносекундных импульсов при их одинарном или двойном дифференцировании $[11,12]$. Питающее напряжение при этом может составлять 5-15 В, что позволяет использовать широко распространенные компактные сетевые блоки питания 220 В/(12-15) В.

В рамках данной концепции были разработаны пикосекундные диодные лазеры, состоящие из компактного блока оптического излучателя и малогабаритного внешнего серийного сетевого блока питания 220 В/12 В, 0.25 А. Блок оптического излучателя содержит 2 задающих кварцевых генератора с управляющим микроконтроллером и с возможностью внешнего управления, цепь синхронизации, низковольтный формирователь наносекундных электрических импульсов, двухступенчатый обостритель сигналов до субнаносекундной длительности на основе дифференцирующих $R C$-цепочек, цепь накачки лазерного диода на основе подстраиваемого источника постоянного тока и регулятора амплитуды тока накачки, а также лазерный диод. Электрическая схема оптического лазерного излучателя приведена на рис. 1.

Для обеспечения многофункциональности данного лазерного излучателя в нем предусмотрены 3 канала задания частоты следования импульсов. Первый - основной канал - реализован на микроконтроллере $M_{1}$ серии Microchip PIC16 с кварцевым резонатором $Q_{1}$; микросхемы $M_{2}$ и $M_{3}$ вырабатывают вспомогательные сервисные сигналы. Контроллер данного типа имеет тактовую частоту 20 МГц и за счет встроенного делителя обеспечивает коэффициенты деления $1,4, \ldots, 262144$, что позволяет получать частоты от 76 Гц до 20 МГц. Можно использовать и резонаторы других типов с частотами, например, 1 или 10 МГц, при этом минимальная частота составит соответственно 4 или 38 Гц. Второй - высокочастотный канал - реализован на кварцевом генераторе $Q_{2}$, его рабочие частоты могут составлять 40, 60 или 80 МГц. Третий - внешний канал - обеспечивает функционирование оптического излучателя от внешних источников запуска, его рабочая частота может достигать 20 МГц.

Применение контроллера позволяет реализовать цифровое управление частотами излучателя при минимуме используемых элементов и максимальной гибкости измерений. Контроллер запоминает последний используемый режим, что дает возможность быстро возобновлять работу без дополнительных настроек. Три канала задания рабочей частоты лазерного излучателя необходимы для упрощения практической адаптации его к используемым потребителями различным времяизмерительным комплексам, каждый из которых может иметь своеобразную архитектуру управляющих сигналов. Например, докомплектация такими достаточно дешевыми пикосекундными излучателями одноквантовых кинетических спектрометров PicoQuant, Hariba и др., имеющихся во многих лабораториях, позволит расширить их 


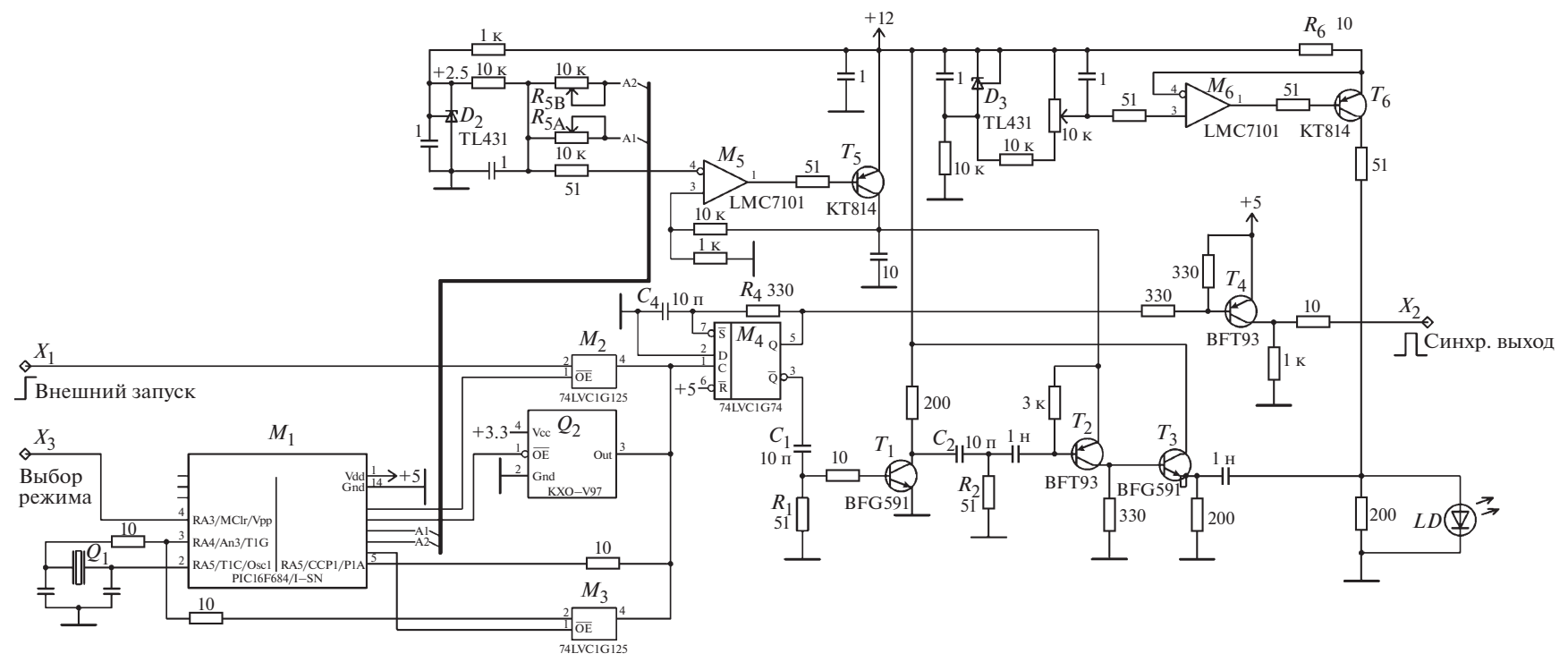

Рис. 1. Электрическая схема оптического лазерного излучателя. $L D$ - лазерный диод.

функциональные возможности. К тому же наличие частот герцевого, килогерцевого и мегагерцевого диапазонов дает возможность легко сочетать измерительные режимы прямой и обращенной шкал для флуорометрии.

Следует отметить, что для большинства таких спектрометров использование кварцованных генераторов системно избыточно. Это связано с тем, что в основе функционирования этих спектрометров лежит старт-стопный принцип регистрации временных интервалов - между стартовым импульсом возбуждения и стоповым импульсом люминесценции. При этом флуктуации частоты стартовых импульсов (в нашем случае частоты лазерного излучателя) на погрешность измерений кинетики люминесценции не влияют. Вместе с тем кварцованность частоты крайне необходима с методологической точки зрения при апробации (аттестации) лазерных излучателей на высокоскоростных стрик-камерах с разрешением 10-25 пс (разрешение во времени самих же одноквантовых спектрометров составляет более 100 пс и определяется в большей мере джиттером используемых фотодетекторов).

В стрик-измерителях оптический сигнал должен быть задержан на 100-150 нс относительно электрического сигнала запуска (синхронизации). Возможно, конечно, использование относительно дорогостоящих и громоздких одномодовых оптоволоконных линий задержки. Более практичной является чисто электрическая синхронизация с запуском от предыдущего лазерного сигнала. В случае кварцованной частоты следования импульсов, нестабильность которой составляет $10^{-6}$, погрешность измерений длительности лазерных сигналов на частоте 20 МГц составляет
0.5 пс. В варианте обычных $R C$-генераторов с их нестабильностью $10^{-4}$ "размытие" регистрируемых оптических сигналов, вносимое неопределенностью подобной синхронизации, составляет 50 пс.

Цепь синхронизации выполнена (см. рис. 1) на микросхемах $M_{2}, M_{3}$, транзисторе $T_{4}$ и вырабатывает управляющие сигналы для используемой потребителями регистрирующей аппаратуры в режиме как внутреннего, так и внешнего запуска. Цепь синхронизации обеспечивает возможность при необходимости вводить дополнительную задержку светового сигнала относительно импульса синхронизации, а также позволяет блоку работать с внешними задающими сигналами с частотами до 20 МГц.

Низковольтный формирователь наносекундных электрических импульсов реализован на одновибраторе $M_{4}$, который вырабатывает положительный импульс длительностью 12 нс для обострителя сигналов и описанной выше цепи синхронизации. Двухступенчатый обостритель сигналов до субнаносекундной длительности выполнен на основе двух дифференцирующих $R C$-цепочек: $R_{1} C_{1}$ и $R_{2} C_{2}$, импульсы с которых усиливаются и инвертируются транзисторами $T_{1}$ и $T_{2}$. При этом формируются импульсы длительностью 2 и 0.8 нс соответственно.

Цепь накачки лазерного диода обеспечивает задание параметров излучаемых световых сигналов - длительности и световой мощности - путем подбора амплитуды импульса накачки и тока смещения для диодов каждого типа. Регулировка амплитуды импульса накачки $U_{L D}$ от 5 до 12 В осуществляется источником постоянного тока на основе операционного усилителя (микросхема $M_{5}$, 


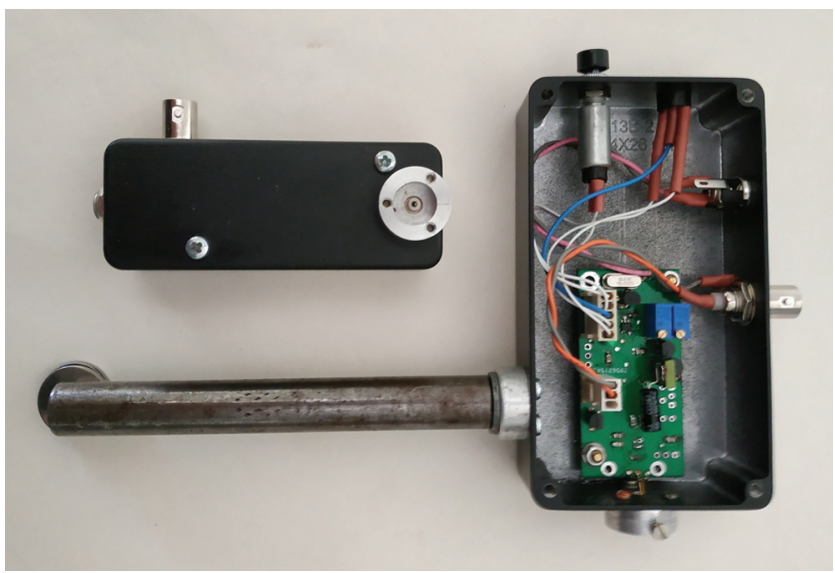

Рис. 2. Общий вид диодного лазера в двух компоновках (один из блоков для наглядности изображен со снятой боковой крышкой)

транзистор $T_{5}$ ) и задаюшего резистора $R_{5}$. Выход данного источника соединен с эмиттером транзистора $T_{2}$ обострителя сигналов; импульс соответствующей величины подается на лазерный диод $L D$ через эмиттерный повторитель на транзистоpe $T_{3}$. Ток смещения лазерного диода $I_{L D}$ в пределах 0-30 мА задается подстраиваемым источником постоянного тока, реализованным на операционном усилителе $M_{6}$ и транзисторе $T_{6}$. В качестве светоизлучательных элементов $L D$ используются серийные лазерные диоды фирм SONY, SONYO, FUJI, SHARP и др.

Вышеописанная электрическая схема оптического излучателя реализована на двухсторонней печатной электрической плате. С установленными электронными компонентами плата имеет габариты $60 \times 30 \times 20$ мм. С учетом субнаносекундных длительностей электрических сигналов геометрические размеры всех соединений минимизированы, особенно это касается цепей накачки лазерного диода. Сам блок излучателя обычно выполнен в металлическом корпусе. Он может иметь различные габариты и конфигурации крепления излучающего лазера. Типичные размеры блока излучателя в коммерческих корпусах составляют $115 \times 64 \times$ $\times 30$ мм и $80 \times 55 \times 25$ мм.

Для ряда применений предусмотрена термостабилизация цепи накачки и лазерного диода: дополнительная микроплата крепится вблизи выходного каскада $L D$, а термохолодильник - на металлическом корпусе излучателя. Малогабаритный внешний серийный сетевой блок питания 220 В/12 В, 0.25 А обеспечивает оптический излучатель необходимым напряжением питания $12 \mathrm{~B}$, его возможные габариты составляют $73 \times 43 \times$ $\times 27$ мм. Масса излучателя с блоком питания составляет 0.2-0.3 кг. Такой излучатель может так- же использоваться для накачки суб- и наносекундных светодиодов [13].

Различные компоновки блока оптического излучателя приведены на рис. 2 (для наглядности в одном из блоков излучателя снята боковая крышка). На блоке излучателя имеется муфта для крепления стандартной оптической стойки диаметром 8 мм, с помощью которой обеспечивается фиксация излучателя в различных оптических устройствах. Вторая муфта предназначена для установки короткофокусной микролинзы, которая необходима в некоторых режимах для фокусировки излучения (например, при FLIM-регистрации биологических объектов), поскольку лазерный пучок ряда широкодоступных лазерных диодов имеет значительную расходимость. Оптические характеристики диодных лазеров - длительность и мощность световых сигналов - определяются режимом накачки лазерных диодов. Для получения пикосекундных импульсов используется режим минимизированной надпороговой накачки - нормируемого превышения током накачки порога лазерной генерации. В этом случае при подаче субнаносекундных электрических импульсов на лазерный диод последний генерирует пикосекундные световые сигналы. Режим минимизированной надпороговой накачки не регламентируется фирмами-производителями. В технической документации в большинстве случаев приводятся лишь параметры диодов для статических режимов эксплуатации при постоянном токе или же для стандартной импульсной накачки.

Генерацию пикосекундных лазерных импульсов в режиме надпороговой накачки начали использовать с момента появления полупроводниковых гетеролазеров [14]. При накачке субнаносекундными электрическими импульсами лазера на гетероструктуре GaAs/AlGaAs, созданной в Физико-техническом институте им. А.Ф. Иоффе, были получены относительно маломощные лазерные импульсы длительностью 20-50 пс на длинах волн 810-850 нм [15]. Режим нормируемой надпороговой генерации используется и для реализации пикосекундных импульсов на более мощных серийных лазерных диодах $[11,16]$.

Для управления генерацией лазерных диодов необходимо контролировать режим их токовой накачки и учитывать возможную температурную трансформацию порога генерации. Актуальность и типичность данной проблемы демонстрируют излучательные ватт-амперные характеристики зависимости выходной оптической мощности $P_{L D}^{\text {opt }}$ от тока смещения $I_{L D}$ при различных температурах $T$ - стандартных лазерных диодов с рабочей длиной волны 405 нм и номинальными мощностями $P_{C W} 50$ и 150 мВт для стационарного режима. Для измерения оптической мощности использовались штатные фотодиоды, встроен- 
ные в корпус лазерных диодов. Полученные зависимости $P_{L D}^{o p t}=P_{L D}^{o p t}\left(I_{L D}, T\right)$ в диапазоне температур от 5 до $70^{\circ} \mathrm{C}$ представлены на рис. 3. Анализ зависимостей позволяет сделать два вывода. Во-первых, диапазон изменения тока смещения $I_{L D}$ от порога генерации до режима стандартной импульсной накачки увеличивается с ростом номинальной мощности лазерных диодов и составляет $25-50$ мА при $P_{C W}=50$ Вт и 25-70 мА при $P_{C W}=$ $=150$ Вт. Во-вторых, вблизи комнатных температур (от 5 до $20^{\circ} \mathrm{C}$ ) изменения выходной мощности $P_{L D}^{o p t}$ и порогового тока $I_{L D}$ незначительны. Это делает излишним температурную стабилизацию диодных лазеров, работающих при комнатных температурах. Однако в полевых условиях эксплуатации температурная стабилизация этих приборов становится необходимой.

Измерения временной зависимости лазерных сигналов проводились на электронно-оптической стрик-камере Hamamatsu C 4334 с разрешением 25 пс. Существенным моментом измерений с такой камерой является обеспечение синхронизации в связи с необходимостью задержки оптического сигнала на 100-150 нс относительно электрического сигнала запуска. В нашем случае, как было указано выше, реализован практичный и удобный вариант с запуском от предыдущего лазерного сигнала. Благодаря использованию кварцевого генератора (с нестабильностью частоты $10^{-6}$ ) при задании частоты следования лазерных сигналов вносимая такой схемой синхронизации погрешность измерений длительности лазерных импульсов на частоте 20 МГц не превысила 0.5 пс.

Режим генерации лазерных диодов задается током смещения $I_{L D}$ и амплитудой импульса накачки $U_{L D}$. В зависимости от величин $I_{L D}$ и $U_{L D}$ peализуются три режима генерации. Временные характеристики этих трех режимов представлены на рис. 4 для лазерного диода SLD-3236VF с номинальной мощностью $P_{C W}=150$ мВт. Слева приведены цифровые полутоновые снимки экрана стрик-камеры: горизонтальной оси соответствует развертка по длине волны (в состав камеры входит спектрометр), а вертикальной - по времени. Справа на рис. 4 изображены временные профили зарегистрированных импульсов лазера. Первый - моноимпульсный пикорежим - достигается при минимизированной надпороговой накачке $\left(I_{L D}=1 \mathrm{мA} \mathrm{и} U_{L D}=5.9 \mathrm{~B}\right)$ с генерацией одиночного лазерного импульса пикосекундной длительности (см. рис. 4а). По мере увеличения $U_{L D}$ до 7.1 В лазерный диод генерирует цуг пикосекундных световых сигналов (см. рис. 4б) - многоимпульсный второй режим. При значительном превышении сигналом накачки порога генерации лазерный диод переходит в третий режим нанорежим - стандартной импульсной накачки
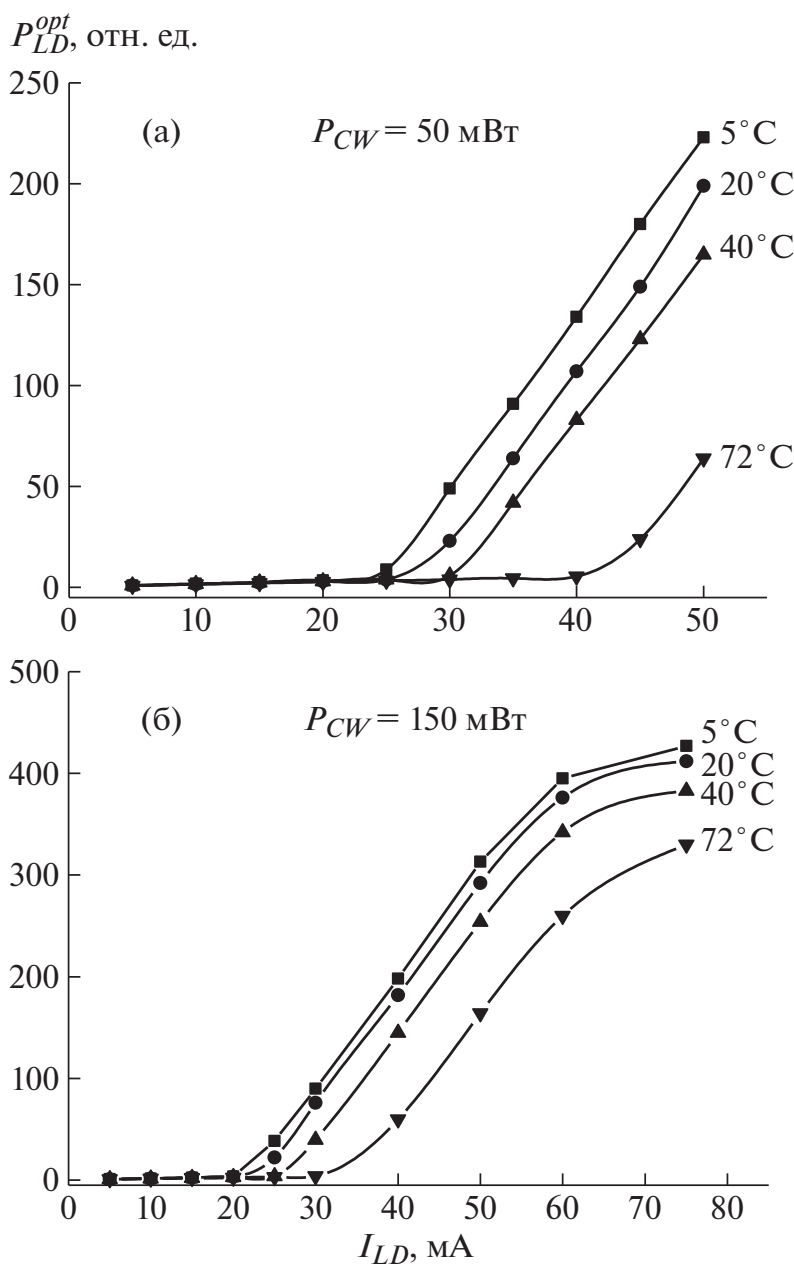

Рис. 3. Излучательные ватт-амперные характеристики - зависимости выходной оптической мощности $P_{L D}^{o p t}$ от тока смещения $I_{L D}$ при различных температуpax $T$ - для стандартных лазерных диодов с номинальной мощностью 50 (а) и 150 мВт (б).

(см. рис. 4в), излучая сигналы длительностью 0.4 нс в 10-15 раз большей яркости, чем в первом режиме. Для спектроскопии интерес представляют пикорежим (для измерений кинетики пико- и субнаносекундных свечений) и нанорежим (для изучения объектов с наносекундными временами жизни флуоресценции, например родамина 6G). С другой стороны, многоимпульсный второй режим может быть весьма полезен для исследований импульсных параметров субнаносекундных фотодетекторов с точки зрения оценки не только быстродействия фотоприемников, но и их переходных характеристик, а также скорости переключения рабочих режимов.

Генерация пикосекундных импульсов в пикорежиме имеет свои особенности для лазерных диодов различных типов. На созданных нами излучателях реализованы следующие минимальные 
(a)

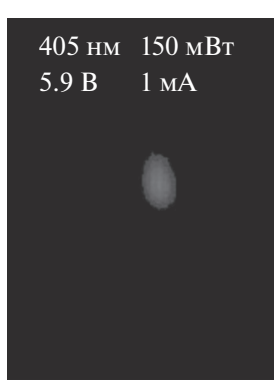

Интенсивность, отн. ед.

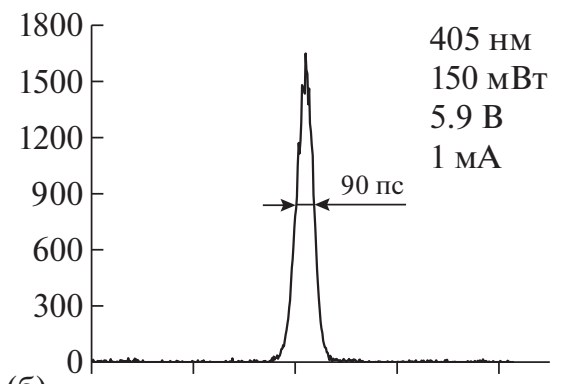

(б)
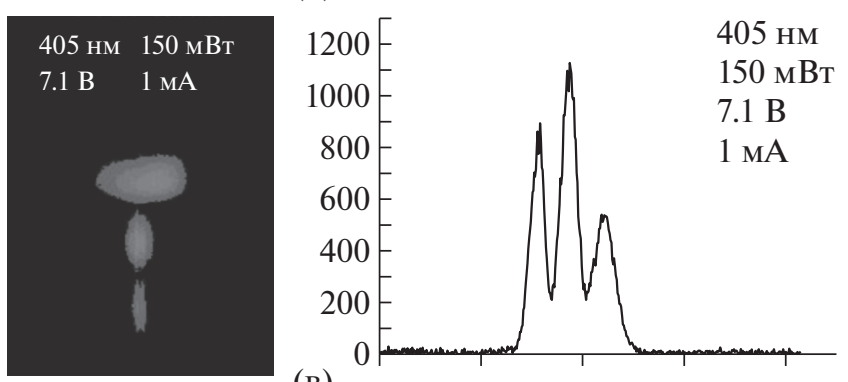

(B)
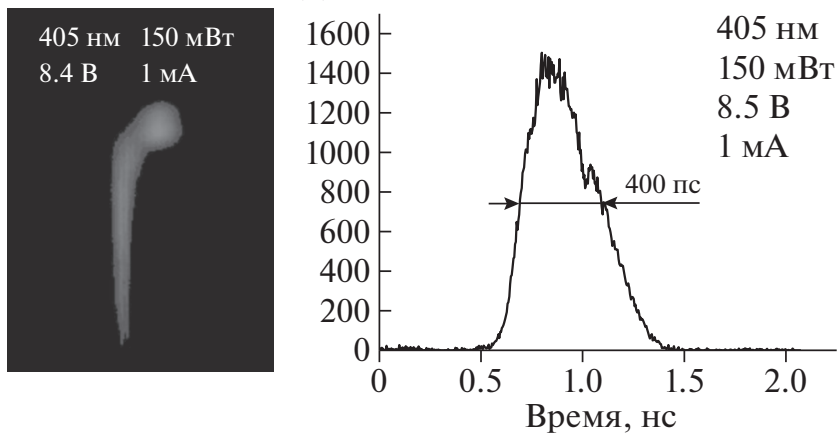

Рис. 4. Три возможных режима генерации лазерного диода SLD-3236VF в зависимости от режима накачки: $\mathbf{a}$ - первый моноимпульсный пикорежим, реализуемый при минимизированной надпороговой накачке; б - второй режим с генерацией многоимпульсной последовательности пикосекундных световых сигналов при превышении минимизированной надпороговой накачки; в - третий режим стандартной импульсной накачки при значительном превышении током накачки порога генерации лазерного диода. Слева представлены цифровые полутоновые изображения экрана стрик-камеры: по горизонтальной оси - длина волны (в состав камеры входит спектрометр), а по вертикальной - время. Справа изображены временные профили зарегистрированных импульсов лазера.

длительности на полувысоте лазерных импульсов для различных длин волн: 405 нм - 70 пс; 46 нм 120 пс; 520 нм - 130 пс; 650 нм - 90 пс; 780 нм 180 пс; 850 нм - 180 пс.

В нанорежиме в зависимости от тока накачки на использованных лазерных диодах генерируются световые сигналы с длительностью на полувысоте от 0.4 до 1.2 нс. Средняя световая мощность регистрировалась измерителем мощности Thorlabs PM100D. В пикорежиме для лазерных диодов с номинальной непрерывной мощностью 50150 мВт при частоте следования лазерных импульсов 20 МГц средняя световая мощность варьируется в диапазоне $0.2-0.4 \mathrm{мB}$, а при частоте 80 МГц - 0.6-1.6 мВт. В нанорежиме средняя световая мощность возрастает и достигает 6-18 мВт на частоте 80 МГц.

Разработанные диодные лазеры успешно заменили в одноквантовых флуорометрах газоразрядные 1-наносекундные воздушные лампы и применяются для измерений кинетики свечений как неорганических, так и органических объектов. В частности, эти лазеры использованы для исследований кинетики быстрой флуоресценции: с длинами волн 405 и 446 нм - рентгеновских люминофоров, а с 446 и 650 нм - индотрикарбоцианиновых красителей в биологических системах [17] и в растворах [18].

\section{СПИСОК ЛИТЕРАТУРЫ}

1. Lakowicz R. Principles of Fluorescence Spectrometry. $3^{\text {rd }}$ ed., NY.: Springer, 2006. P. 98-157. https://doi.org/10.1007/978-0-387-46312-4

2. Беккер В., Желзов А., Чеславский В. // Фотоника. 2015. T. 53. № 5. C. 52.

3. www.alphalas.com.

4. www.becker-hickl.com.

5. www.edinst.com.

6. www.hamamatsu.com.

7. www.horiba.com.

8. www.nktphotonics.com.

9. www.picoquant.com.

10. Васильев Р.В., Лубсандоржиев Б.К., Похил П.Г. // ПТЭ. 2000. № 4. С. 148.

11. Uhring W., Zint C.-V., Bartinger J. // Proc. SPIE. 2004. V. 5452. P. 583. https://doi.org/10.1117/12.545038

12. Sulkes M., Sulkes Z. // Am. J. Phys. 2011. V. 79. № 11. P. 1104. https://doi.org/10.1119/1.3620415

13. Воропай Е.С., Ермалицкий Ф.А., Радько А.Е., Самиов М.П. // ПТЭ. 2020. № 1. С. 151. https://doi.org/10.31857/S0032816220010097

14. Алферов Ж.И., Журавлев А.Б., Портной Е.Л., Стельмах Н.M. // Письма в ЖТФ. 1986. Т. 12. № 18. C. 1093.

15. Ермалиикий Ф.А., Костюкевич Н.К., Прохоренко А.С., Устинов Б.П. // ПТЭ. 1991. № 4. С. 241.

16. Дюделев В.В., Зазулин С.В., Колыхалова Е.Д., Лосев С.Н., Дерягин А.Г., Кучинский В.И., Ефанов М.В., Соколовский Г.С. // Письма в ЖТФ. 2016. Т. 42. № 24. С. 1.

17. Самиов М.П., Тарасов Д.С., Горященко А.С., Казачкина Н.И., Жердева В.В., Савицкий А.П., Меерович И.Г. // Журнал Белорусского гос. университета. Физика. 2018. № 1. C. 34.

18. Белько Н.В., Самиов М.П., Тихомиров С.А., Буганов О.В. // Журнал прикладной спектроскопии. 2020. Т. 87. № 5. C. 752.

https://doi.org/10.1007/s10812-020-01078-Z 